Research Paper

\title{
NUSAP1 promotes invasion and metastasis of prostate cancer
}

\author{
Catherine A. Gordon ${ }^{1}$, Xue Gong ${ }^{1,2}$, Durga Ganesh ${ }^{1}$ and James D. Brooks ${ }^{1,3}$ \\ ${ }^{1}$ Department of Urology, Stanford University School of Medicine, Stanford, CA, 94305, USA \\ ${ }^{2}$ Department of Pathology, Stanford University School of Medicine, Stanford, CA, 94305, USA \\ ${ }^{3}$ Stanford Cancer Institute, Stanford University School of Medicine, Stanford, CA, 94305, USA \\ Correspondence to: James D. Brooks, email: jdbrooks@stanford.edu \\ Keywords: NUSAP1, invasion, migration, metastasis, prostate cancer \\ Received: September 18, $2016 \quad$ Accepted: January 25, $2017 \quad$ Published: February 22, 2017 \\ Copyright: Gordon et al. This is an open-access article distributed under the terms of the Creative Commons Attribution License (CC-BY), \\ which permits unrestricted use, distribution, and reproduction in any medium, provided the original author and source are credited.
}

\begin{abstract}
We have previously identified nucleolar and spindle associated protein 1 (NUSAP1) as a prognostic biomarker in early stage prostate cancer. To better understand the role of NUSAP1 in prostate cancer progression, we tested the effects of increased and decreased NUSAP1 expression in cell lines, in vivo models, and patient samples. NUSAP1 promotes invasion, migration, and metastasis, possibly by modulating family with sequence similarity 101 member $B$ (FAM101B), a transforming growth factor beta 1 (TGFß1) signaling effector involved in the epithelial to mesenchymal transition. Our findings provide insights into the importance of NUSAP1 in prostate cancer progression and provide a rationale for further study of NUSAP1 function, regulation, and clinical utility.
\end{abstract}

\section{INTRODUCTION}

Considerable controversy and confusion surround the diagnosis and management of clinically localized prostate cancer, the most common malignancy in men in the USA and Europe [1]. Widespread screening for prostate cancer in the USA has been associated with a $75 \%$ drop in metastatic disease at presentation [2], and randomized trials in Europe show survival benefits to PSA screening and prostate surgery $[3,4]$. However, randomized trials of screening and surgery in the USA have shown no survival benefit $[5,6]$, and a consensus has developed that localized prostate cancer is over-diagnosed and over-treated, even in the European randomized trials. In response to these conflicting data, some recommend against screening and treatment of clinically localized prostate cancer [7], others advocate for increased use of active surveillance [8-10], while others seek to develop approaches to better predict the natural history of localized prostate cancer to better select men who need aggressive therapies.

Previously, we identified NUSAPI as a candidate prognostic biomarker in patients undergoing radical prostatectomy [11]. In several diverse datasets, increased NUSAP1 expression is associated with recurrence after radical prostatectomy [11], and it is found in prognostic gene sets associated with high grade compared to low grade prostate cancer [12], two commercial platforms used to predict prognosis (Prolaris from Myriad Genetics and Decipher from GenomeDx Biosciences) [13-16], and a set of transcripts upregulated in a model of castration resistant prostate cancer [17]. NUSAP1 overexpression is also prognostic in other cancer types, including melanoma $[18,19]$, breast cancer [20, 21], glioblastoma [22], hepatocellular carcinoma [23], and meningioma [24]. The breadth of studies implicating NUSAP1 suggests it plays an important functional role in cancer progression.

Current understanding of NUSAP1's function is limited, although existing data suggests it could simply be a marker of proliferation [25]. NUSAP1 is an essential microtubule and chromatin-binding protein that crosslinks microtubules during mitosis [26-28], modulates the dynamics of kinetochore microtubules [29], and governs chromosome oscillation [30]. NUSAP1 expression is regulated by E2F transcription factor $1(\mathrm{E} 2 \mathrm{~F} 1)$ and by loss of retinoblastoma-associated protein 1 (RB1), an important molecular pathway that becomes altered in aggressive forms of prostate cancer $[11,31,32]$. To better understand the functional role of NUSAP1 in prostate cancer, we explored the effects of overexpression and knockdown of NUSAP1 in in vitro and in vivo models. We find that NUSAP1 has limited effects on proliferation, but rather is associated with development of metastatic disease, possibly through modulation of expression of FAM101B. FAM101B is involved in cell shape remodeling during 
the epithelial to mesenchymal transition and is a signaling effector of TGF $\beta 1[33,34]$, which promotes invasion and metastatic spread during prostate tumor progression [35].

\section{RESULTS}

\section{NUSAP1 promotes invasion and migration}

We previously found that NUSAP1 is overexpressed in recurrent prostate cancer and is regulated, at least in part, by loss of RB1 via the RB1/E2F1 axis $[11,31]$. Since knockdown of NUSAP1 results in reduced invasion of PC-3 prostate cancer cells [11], we hypothesized that overexpression of NUSAP1 might have the opposite effect, leading to increased invasion of prostate cancer cells. To test this hypothesis, we used lentiviral infections to overexpress NUSAP1 or EGFP control in DU145 or PC-3 cells, verified overexpression by reverse transcription-quantitative polymerase chain reaction (RT-qPCR) and western blot (Supplementary Figures $1 \mathrm{~A}$ and $1 \mathrm{~B})$, and plated cells in Matrigel invasion chambers (BD Biosciences, Franklin Lakes, NJ, USA). Overexpression of NUSAP1 increased invasion of both DU145 and PC-3 cells compared to controls (Figure 1A and 1B). Furthermore, wound healing assays showed that overexpression of NUSAP1 (Supplementary Figures 1A and $1 \mathrm{~B}$ ) led to increased migration, while knockdown of NUSAP1 (Supplementary Figure 1B) led to reduced migration of DU145 or PC-3 cells (Figures 1C-1E).

NUSAP1 binds DNA to the mitotic spindle and we have shown that knockdown of NUSAP1 results in reduced proliferation of DU145, LNCaP, PC-3, and PC-3-RB1 low prostate cancer cells grown in culture $[11,31]$, yet it was unknown whether NUSAP1 overexpression would enhance proliferation. Overexpression of NUSAP1 or EGFP control in DU145, LNCaP, PC-3, or 22Rv1 prostate cancer cell lines using a lentiviral vector (Supplementary Figures 1A-1D) did not significantly affect proliferation rates over a period of 5 days (Supplementary Figures 2A-2D). Flow cytometry confirmed that overexpression of NUSAP1 did not significantly alter cell cycle stages or apoptosis (Supplementary Figures $3 \mathrm{~A}$ and $3 \mathrm{~B}$ ); however, knockdown of NUSAP1 (Supplementary Figures 1B and 1C) resulted in a significant increase in the number of cells in the G2/M phase of the cell cycle and number of apoptotic cells (Supplementary Figures 3C and 3D).

To further determine if NUSAP1 expression would affect proliferation in vivo, we used lentiviral infections to overexpress or knockdown NUSAP1 or controls in PC-3-luc2 cells (PC-3 cells that stably express the firefly luciferase gene), verified overexpression or knockdown of NUSAP1 by RT-qPCR and western blot (Supplementary Figure 1E), and tested whether NUSAP1 overexpression or knockdown affected growth of PC-3-luc2 cells in mouse xenografts. When measuring tumor volume using total flux bioluminescence, there was no significant difference in bioluminescence of NUSAP1 overexpressing versus $E G F P$ overexpressing subcutaneous tumors by 50 days (Figure 2A and 2B). Caliper measurements, however, demonstrated a relatively small but significant difference in the size of NUSAP1 overexpressing versus EGFP overexpressing subcutaneous tumors by 41 days (Supplementary Figure 4A). After harvesting tumors, RT-qPCR demonstrated continued overexpression in the lentiviral transfected tumors (Supplementary Figure 4B). Knockdown of NUSAP1 expression produced a significant reduction in tumor size measured by bioluminescence and calipers (Figures 2C, 2D, and Supplementary Figure 4C). After harvesting tumors, RTqPCR demonstrated continued knockdown in the lentiviral transfected tumors when using NUSAP1 shRNA \#2, but no significant difference when using NUSAP1 shRNA \#1 (Supplementary Figure 4D). Tumor weights were also lower when NUSAPI had been knocked down (Figure $2 \mathrm{E})$, consistent with decreased tumor volume and reduced proliferation.

\section{NUSAP1 is associated with metastasis in patient samples and promotes metastasis in mice}

Since overexpression of NUSAP1 is sufficient to result in increased invasion and migration, we used publicly available gene expression datasets (www.ncbi.nlm.nih.gov/ geo/) to investigate the relative levels of gene expression in normal prostate tissue, primary prostate cancer, and metastatic prostate cancer [36-38]. Intriguingly, NUSAP1 transcripts were highest in metastatic samples and lowest in noncancerous samples (Figure 3A and 3B). Based on this observation, we tested whether NUSAP1 overexpression would lead to increased metastasis while NUSAP1 knockdown would lead to reduced metastasis in our mouse xenograft models. By ex vivo bioluminescence imaging, we measured luciferase expression in each lung, right axillary lymph node, and left axillary lymph node of sacrificed mice that had NUSAP1 overexpression or knockdown in flank tumors. In this relatively small set of mouse xenografts, overexpression of NUSAP1 was associated with a relative increase in the percentage of mice with metastases, while knockdown of NUSAP1 was associated with a reduction (Supplementary Table 1).

We then generated additional mouse xenografts of PC-3-luc2 cells in which NUSAP1 or controls were overexpressed or knocked down. To quantitatively assess the extent of metastases, we used RT-qPCR for humanspecific GAPDH expression versus universal (both human and mouse) GAPDH expression as described previously [39], and tested relative GAPDH transcript levels in each lung, right axillary lymph node, left axillary lymph node, right femoral bone marrow, liver, and spleen. For all tissue sites combined, the percentage of mice with metastases was significantly higher when NUSAP1 was overexpressed in the primary tumor compared to $E G F P$ overexpression 

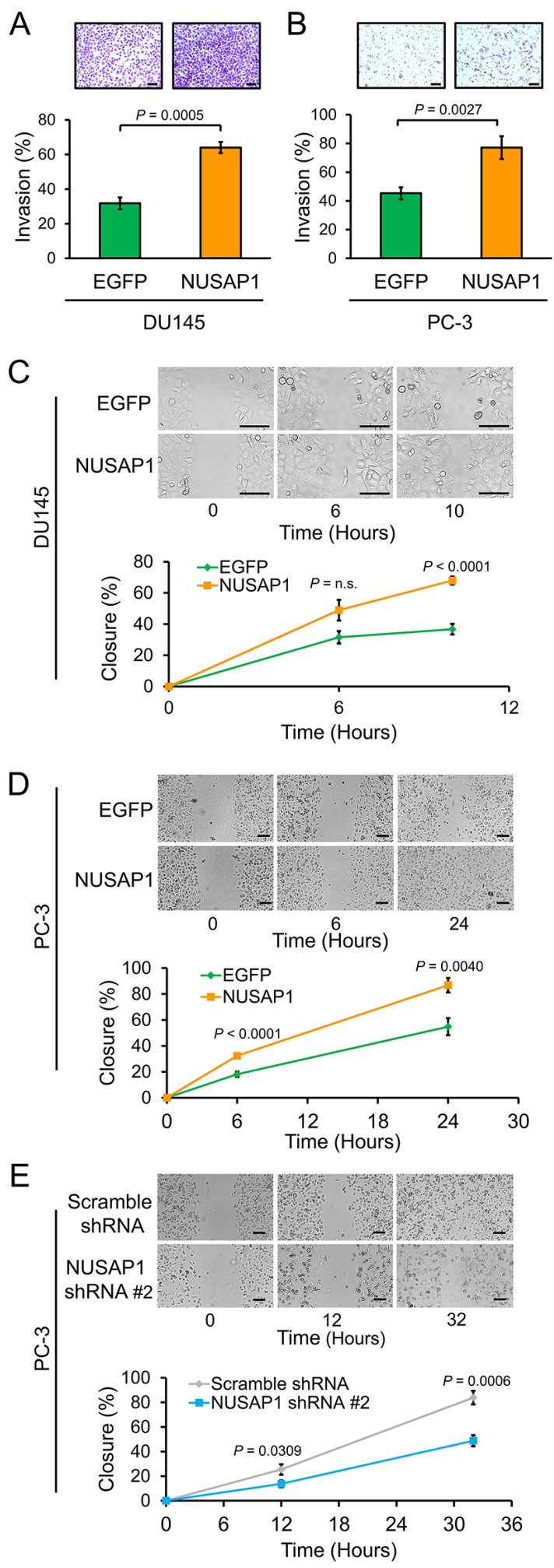

Figure 1: NUSAP1 overexpression increases invasion and migration of prostate cancer cells. $\mathrm{A}$ and $\mathrm{B}$. Matrigel chambers were used to perform invasion assays with (A) DU145 and (B) PC-3 cells stably overexpressing NUSAP1 or EGFP control. Representative images show invasion of Matrigel membranes stained with $0.5 \%$ crystal violet. Bars: mean \pm SEM (standard error of the mean). C, $\mathbf{D}$, and E. Confluent monolayers of (C) DU145 and (D and E) PC-3 cells stably overexpressing or underexpressing NUSAP1 or controls were abraded and then monitored over time for wound channel closure. Representative images show wound channel closure over time. The migratory rate was determined by measuring wound channel area as a function of time using NIH Image J software. Points: mean \pm SEM; n.s.: not significant. All scale bars: $100 \mu \mathrm{m}$. All $P$-values were calculated using the two-tailed Student's t-test. 

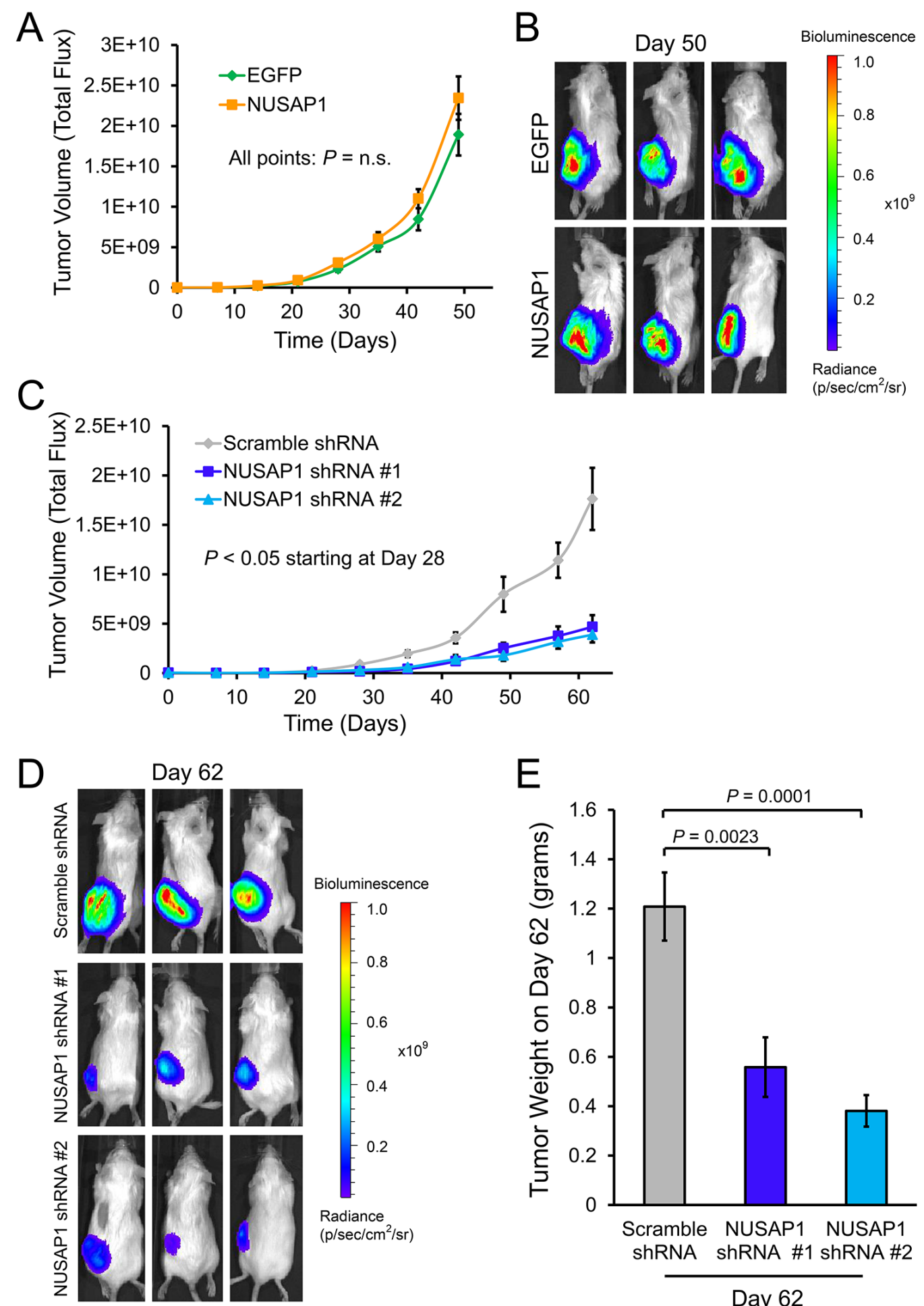

Figure 2: Effects of NUSAP1 overexpression or underexpression on tumor volume as measured by bioluminescence. A. Bioluminescence measurements of tumor volume over time in mice with tumors overexpressing NUSAP1 versus EGFP. Points: mean \pm SEM. EGFP: $\mathrm{n}=23$. NUSAP1: $\mathrm{n}=23$. B. Representative images of tumor bioluminescence on day 50 in mice with tumors overexpressing NUSAP1 versus EGFP control. C. Bioluminescence measurements of tumor volume over time in mice with tumors underexpressing NUSAP1 versus control. Points: mean \pm SEM. Scramble shRNA: $\mathrm{n}=12$; NUSAP1 shRNA \#1: $\mathrm{n}=10 ;$ NUSAP1 shRNA \#2: $\mathrm{n}=9$. D. Representative images of tumor bioluminescence on day 62 in mice with tumors expressing scramble shRNA, NUSAP1 shRNA \#1, or NUSAP1 shRNA \#2. E. Average tumor weights of mice on day 62 with tumors expressing scramble shRNA, NUSAP1 shRNA \#1, or NUSAP1 shRNA \#2. Bars: mean \pm SEM. Scramble shRNA: $\mathrm{n}=12$; NUSAP1 shRNA \#1: $\mathrm{n}=11$; NUSAP1 shRNA \#2: $\mathrm{n}=9$. All $P$-values were calculated using the two-tailed Student's t-test. 
(Supplementary Figure 5A). When looking at individual tissues, the percentage of mice with metastases was also higher when NUSAP1 was overexpressed in each tissue examined except for the spleen (Supplementary Figures 5B-5G). Likewise, the human GAPDH/universal GAPDH transcript levels, a surrogate for metastatic burden, were higher, overall, in NUSAP1 overexpressing tumors (Figure 4A). Interestingly, NUSAP1 overexpression resulted in a statistically significant increase in the quantity of metastases found in the lungs and right axillary lymph nodes (Figure 4B and 4C), but not in other tissues examined (Figures 4D-4G).

\section{NUSAP1 overexpression or knockdown leads to differentially expressed genes involved in organismal injury and abnormalities, cancer, and cell death and survival}

To gain insights into gene expression alterations induced when NUSAP1 is modulated, we used lentiviral infections to overexpress or knockdown NUSAP1 in DU145 or PC-3 cells for 72 or 96 hours, verified overexpression or knockdown by RT-qPCR and western blot (Supplementary Figures 1A and 1B), and performed
RNA sequencing (RNA-Seq). When NUSAP1 was overexpressed in PC-3 cells for 96 hours, RNA-Seq showed that NUSAP1 was overexpressed 3.1-fold and was associated with 185 differentially expressed genes (78 upregulated and 107 downregulated) compared to EGFP control cells (fold-change $\geq 1.5$ and adjusted $P<$ 0.05; Supplementary Table 2). Ingenuity Pathway Analysis revealed that tumor progression was predicted to increase based on the direction of differentially expressed genes $(P$ $=0.0002$; Z-score $=2.390$ ). In addition, Ingenuity Pathway Analysis revealed that the differentially expressed genes were involved in functions that include cancer, cellular movement, and cell morphology (Figure 5A).

Knockdown of NUSAP1 expression in DU145 or PC-3 cells stably using two different shRNAs to NUSAP1 versus scramble shRNA control was performed for 72 or 96 hours post initial infection. RNA-Seq showed that NUSAP1 knockdown decreased NUSAP1 expression 3.1-fold to 22.6-fold compared to control, and revealed 144 transcripts (58 upregulated and 86 downregulated) that were modulated in all eight knockdown experiments (Figures 5B and 5C and Supplementary Table 3). This 144-member gene signature was associated with functions that include cancer, cellular assembly and organization,

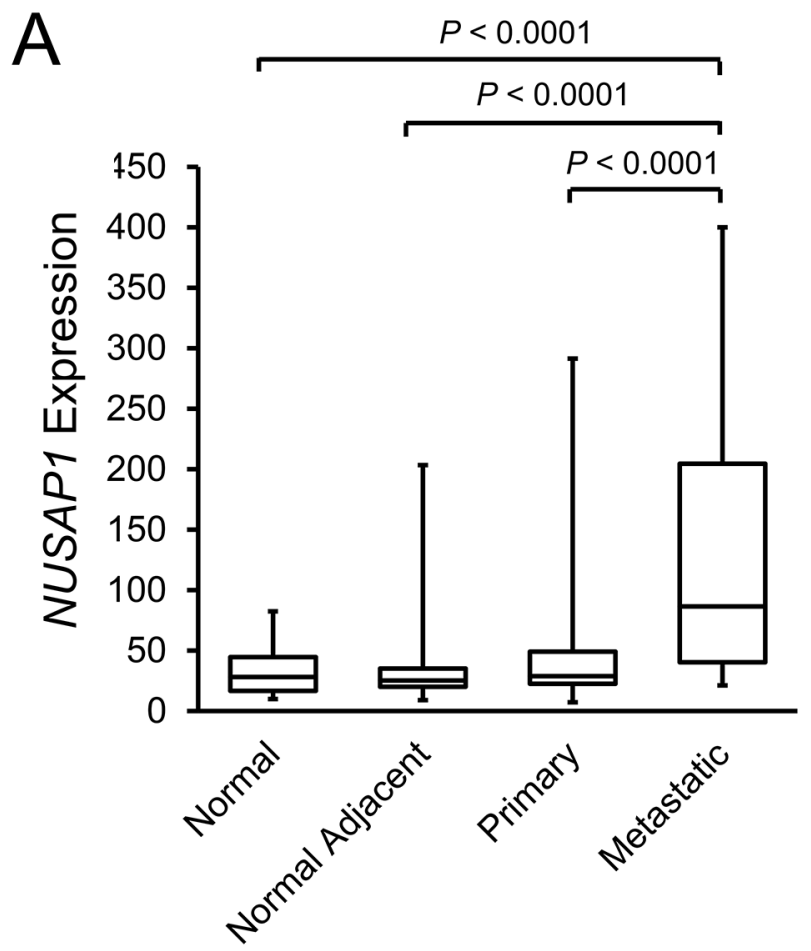

Yu YP et al., 2004 and Chandran UR et al., 2007

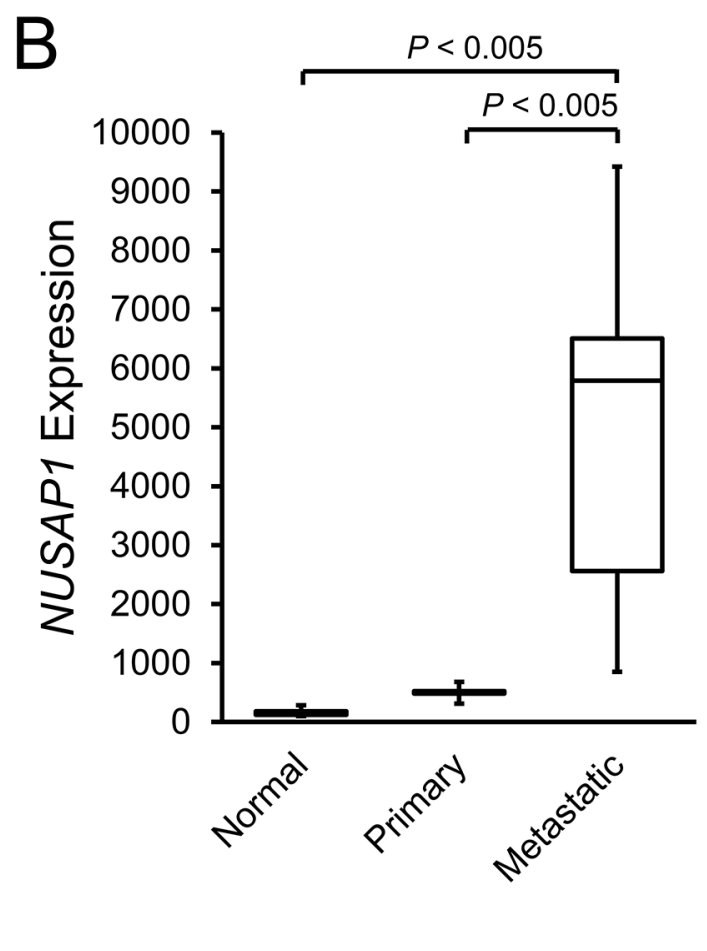

Varambally S et al., 2005

Figure 3: NUSAP1 transcripts are increased in patient metastatic prostate tumors. A. Box plots of NUSAP1 expression in the Yu YP et al., 2004 [36] and Chandran UR et al., 2007 [37] datasets (GEO Accession: GDS2547; GEO Profile: 34888857). Normal: $\mathrm{n}$ = 17; Normal Adjacent: $\mathrm{n}=58$; Primary: $\mathrm{n}=64$; Metastatic: $\mathrm{n}=25$. B. Box plots of NUSAP1 expression in the Varambally $\mathrm{S}$ et al., 2005 [38] dataset (GEO Accession: GDS1439; GEO Profile: 14252725). Normal: $\mathrm{n}=6$; Primary: $\mathrm{n}=7$; Metastatic: $\mathrm{n}=6$. All $P$-values were calculated using the two-tailed Student's t-test. 
and tissue development (Figure 5D). Interestingly, the top three functions (organismal injury and abnormalities, cancer, and cell death and survival) were the same in the overexpression and knockdown experiments (Figure 5A and 5D).

To determine whether the gene signatures modulated by NUSAP1 overexpression or knockdown in prostate cancer cell lines relate to the behavior of human prostate cancers, we used the Significance Analysis of Microarrays technique (SAM) [40] to identify genes positively and negatively correlated with NUSAP1 in a prostate cancer dataset with well annotated clinical follow-up [41]. We identified 3,414 transcripts correlated with NUSAP1 expression (2,610 positively correlated and 804 negatively correlated; FDR $=0.0455)$. Of the 185 transcripts found in NUSAP1 overexpressing PC-3 cells in culture, 104 were among the 3,414 transcripts and were both significantly enriched and differentially expressed in the same direction
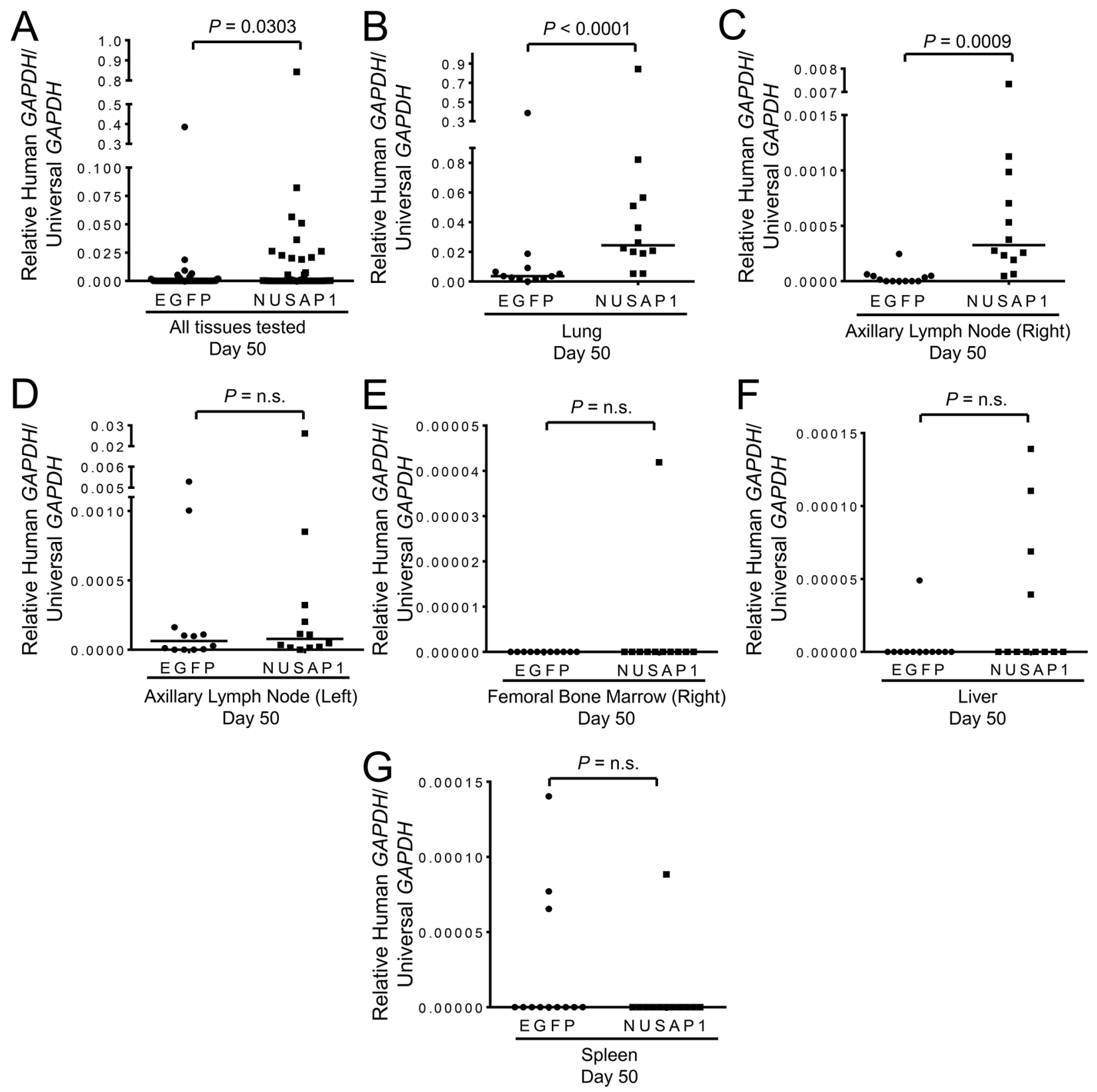

Figure 4: NUSAP1 overexpression significantly increases metastases in a PC-3-luc2 xenograft model. Mice bearing PC3-luc2 flank tumors overexpressing NUSAP1 or EGFP were assessed for metastases to the lung, axillary lymph nodes (right and left), femoral bone marrow (right), liver, or spleen by measuring expression levels of human GAPDH relative to universal GAPDH by RT-qPCR. Measurements of metastases in A. all six tissue sites combined and the B. lung, C. right axillary lymph node, D. left axillary lymph node, E. right femoral bone marrow, F. liver, and G. spleen. All horizontal lines represent the median. All $P$-values were calculated using the Mann-Whitney U test. 
(Hypergeometric test; $P=0.0152$ ). Of the 144 transcripts differentially expressed upon NUSAP1 knockdown in cell culture, 100 of them were found among the 3,414 transcripts and were both significantly enriched and differentially expressed in the same direction (Hypergeometric test;
$P=0.0013)$. Furthermore, when we used the 104 and 100 gene sets to perform unsupervised hierarchical clustering, patient samples segregated into two groups (Figure 6A and $6 \mathrm{~B})$ that displayed significantly different patient survival (Figure 6C and 6D). Notably, the worse outcome group
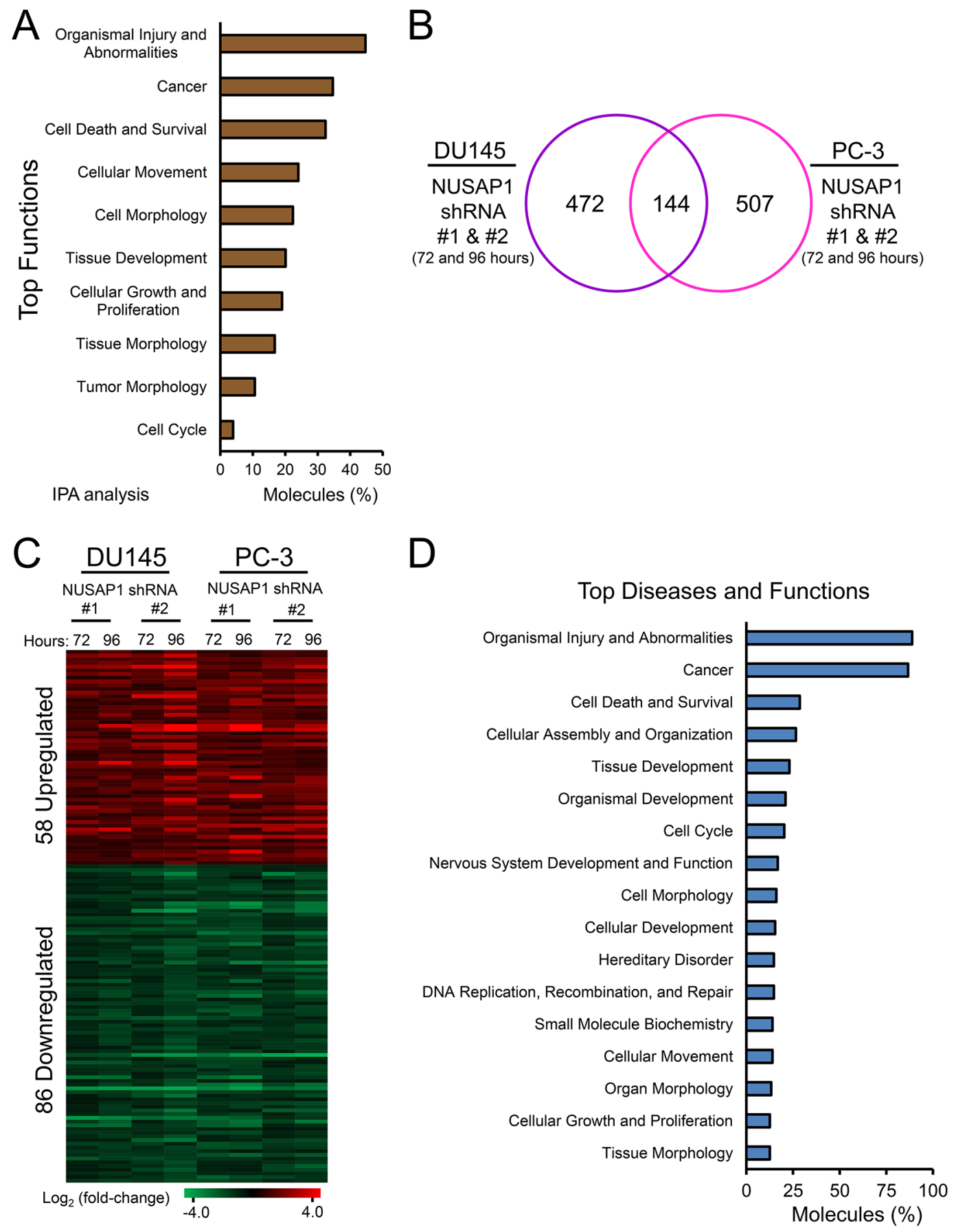

Figure 5: NUSAP1 overexpression or knockdown leads to differentially expressed genes associated with cancer progression. A. Graph illustrates enriched functions of the 185 differentially expressed genes when NUSAP1 is overexpressed in PC-3 cells as determined by Ingenuity Pathway Analysis. B. A common 144-member gene signature of differentially expressed transcripts is revealed after NUSAP1 knockdown in DU145 and PC-3 cells (fold-change $\geq 1.5$ and adjusted $P<0.05$ ). C. Heatmap of the 144-member gene signature. D. Graph illustrates enriched functions of the 144 differentially expressed genes when NUSAP1 is knocked down in DU145 and PC -3 cells as determined by Ingenuity Pathways Analysis. 
from the NUSAP1 overexpression gene signature (cluster 1 in Figure 6C) showed significant enrichment for expression in the same direction (increased or decreased expression) as when NUSAP1 was overexpressed in vitro, while the better outcome group (cluster 2 in Figure 6C) was inversely correlated with the direction of gene expression (Fisher's exact test; $P<0.001)$. Likewise, the better outcome group from the NUSAP1 knockdown signature (cluster 1 in Figure 6D) showed significant enrichment for expression in the same direction as the in vitro experiments, while the worse outcome group (cluster 2 in Figure 6D) was inversely correlated to the knockdown gene expression direction (Fisher's exact test; $P<0.001$ ).

\section{FAM101B is a potential downstream effector of NUSAP1}

Comparison of the NUSAP1 overexpression and knockdown datasets showed that FAM101B was induced in response to $N U S A P 1$ overexpression and suppressed when NUSAP1 was knocked down. FAM101B is a filamin binding protein that is upregulated by TGF $\beta 1$, participates in skeletal development, and is involved in cell shape remodeling during the epithelial to mesenchymal transition $[33,34]$. Since FAM101B is involved in pathways involved in cancer cell invasion and metastasis, we wondered if FAM101B might play a role downstream of

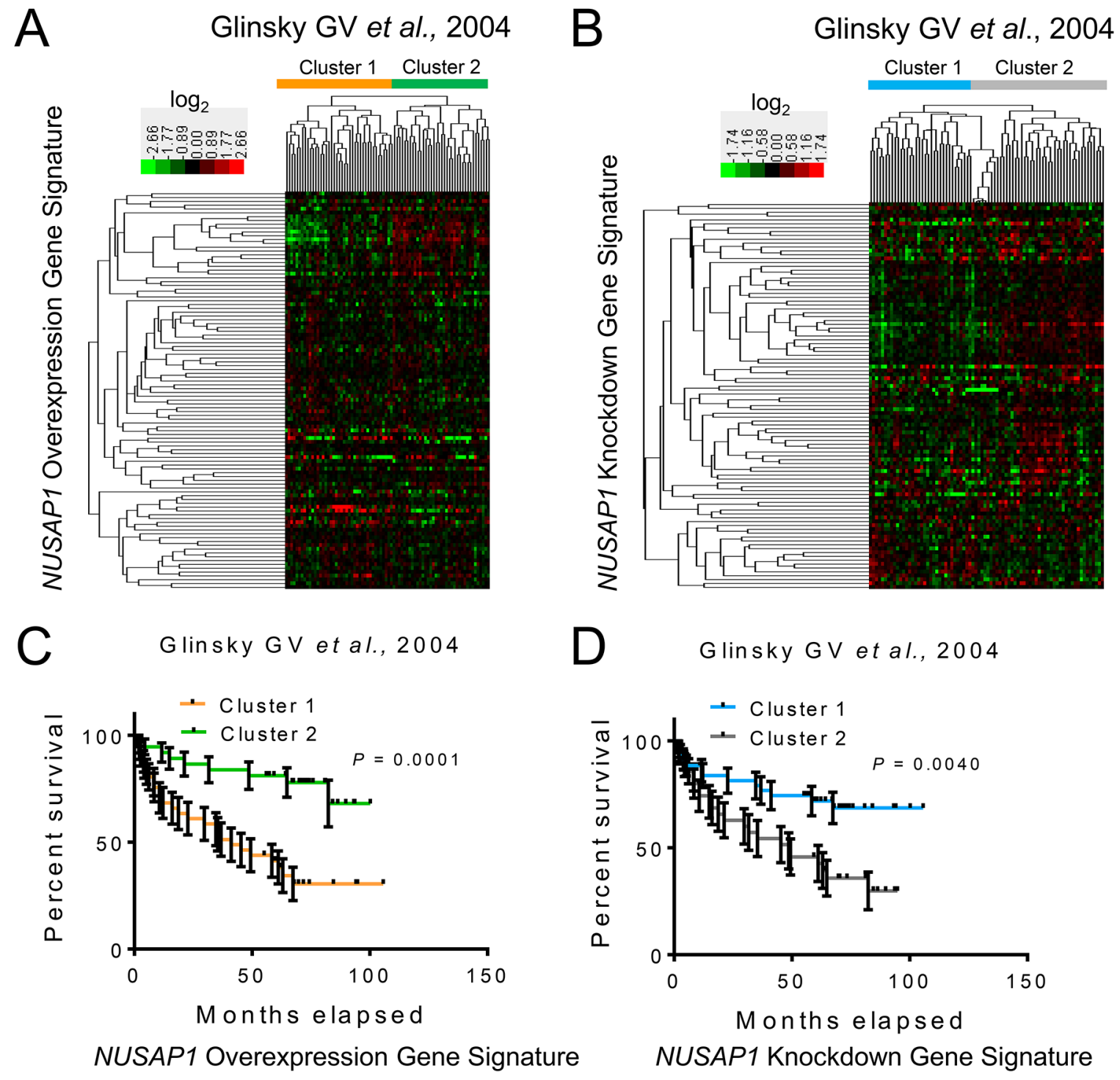

Figure 6: NUSAP1 overexpression and knockdown gene signatures are prognostic in human prostate cancer samples. A and B. Hierarchical clustering of the Glinsky GV et al., 2004 [41] prostate cancer samples across the (A) 104 genes affected by NUSAP1 overexpression and the (B) 100 genes affected by NUSAP1 knockdown. (A) Orange and green bars represent the two clusters when using the NUSAP1 overexpression gene signature. (B) Blue and gray bars represent the two clusters when using the NUSAP1 knockdown gene signature. C and D. Kaplan-Meier survival analysis comparing the two clusters from the NUSAP1 (C) overexpression and (D) knockdown gene signatures. Error bars: \pm SEM. $P$-values were calculated using the log-rank test. 
NUSAP1 in making prostate cancer cells more aggressive. After verifying that $F A M 101 B$ expression is upregulated in DU145, PC-3, and PC-3-luc2 cells overexpressing NUSAP1 (Supplementary Figures 6A-6C), we knocked down FAM101B expression in DU145-NUSAP1 (DU145 cells stably overexpressing NUSAP1) and PC-3-NUSAP1 (PC-3 cells stably overexpressing NUSAP1) cells using two different shRNAs (Supplementary Figures 6D and $6 \mathrm{E}$ ). Invasion and wound healing assays showed that knockdown of FAM101B reversed the effects of NUSAP1 overexpression, leading to reduced invasion (Figure 7A) and migration rates (Figure 7B and 7C). In patient gene expression datasets, FAM101B expression was significantly elevated in metastatic tumors of the Yu YP et al. and Chandran UR et al. datasets [36, 37] (Supplementary Figure 6F), but not in the metastatic tumor samples from Varambally S et al. [38], although the latter dataset included only 6 patient samples (Supplementary Figure 6G). Furthermore, in the gene expression dataset from Taylor et al. [42], where we have previously shown that NUSAP 1 expression levels are significantly correlated with recurrence after surgery [11], FAM101B and NUSAP1 gene expression levels in all 216 tumors had a tendency to co-occur (Log Odds Ratio $=0.969 ;$ Z-score \pm 2.0 ; www . cbioportal.org/) [43, 44].

\section{DISCUSSION}

While NUSAP1 has been linked to proliferation based on its role in assembly of the mitotic spindle, our results provide compelling evidence that NUSAP1 plays a direct role in driving prostate cancer progression. In prostate cancer cell lines in vitro, overexpression of NUSAP1 did not increase proliferation, but did increase invasion and migration, and depletion of NUSAP1 decreased proliferation, invasion, and migration. Modest NUSAP1 overexpression in prostate cancer xenografts, comparable to levels observed in human prostate cancers, significantly increased metastases and modestly affected tumor volume. Consistent with these findings, analysis of human prostate cancer samples showed that NUSAPI is highly expressed in metastases, compared to localized tumors. Overexpression and knockdown of NUSAP1 produced changes in gene expression programs associated with tumor progression, and these gene sets predict patient outcomes in patients undergoing surgery for localized prostate cancer. One gene consistently modulated, FAM101B, correlates with NUSAP1 expression in patient samples and appears to be an important downstream effector of NUSAP1 in tumor progression since knockdown of FAM101B abolished NUSAP1's effects on prostate cancer cell invasion and migration. Our data suggests a direct functional role of NUSAP1 in tumor progression, bolstering its role as a prognostic biomarker and warranting further investigation into its function and therapeutic potential.
Elevated NUSAP1 expression is associated with increased aggressiveness and poor patient outcome in prostate cancer [11]. Loss of RB1 is common in prostate cancer [45-47], controls progression into castrationresistant prostate cancer [32, 45-47], and is a mechanism responsible for overexpression of NUSAP1 [31]. Overexpression of androgen receptor (AR) is a common event in castration-resistant prostate cancer [48-52] and may be directly related to overexpression of NUSAP1. In LNCaP cells that stably overexpress $A R, N U S A P 1$ expression is significantly increased [53]. Although a putative AR binding site in the NUSAP1 promoter has not been identified, an AR binding site approximately $100 \mathrm{~kb}$ upstream of the NUSAP1 transcription start site has been reported [53], suggesting that AR might regulate NUSAP1 expression via this enhancer region. NUSAP1 expression increases in response to androgen treatment in LNCaP cells [54]; however, NUSAP1 is associated with the mitotic spindle and androgen treatment of prostate epithelial cells induces proliferation. Further testing is necessary to determine if there is a direct connection between AR and NUSAPI expression.

Surprisingly, little work has examined the role of NUSAP1 in cancer, despite several reports documenting that overexpression of NUSAP1 is associated with significantly worse outcome [55]. Given its critical role in mitosis, knockdown of NUSAP1 results in decreased proliferation, cell cycle arrest in $\mathrm{G} 2 / \mathrm{M}$, and induction of apoptosis [26, 56, 57], as we have observed here. Transient high-level overexpression of NUSAP1 can also be toxic to cells $[26,56]$, limiting previous efforts to study its potential role in carcinogenesis and progression. Unlike previous reports, we used lentiviral infections, rather than transfections, to overexpress NUSAP1. This approach resulted in a relatively lower level of NUSAP1 expression, demonstrated by RT-qPCR, western blot, and RNA-Seq, such that the levels of overexpression were in the same range as has been observed in human prostate cancers and other malignancies. Very likely, this lower level of induction was due to selective outgrowth of cells that had fewer copies of NUSAP1 cDNA per cell. Regardless, the modest inductions we achieved allowed us to investigate the effects NUSAP1 overexpression.

Although previous studies have suggested that knockdown of NUSAP1 decreases invasion of cells in vitro [11, 31], the effects of knockdown on cell growth, including cell cycle arrest and apoptosis, could confound determination of a direct role of NUSAP1 in tumor progression since dying or arrested cells are less likely to invade. However, since modest increases in expression were achieved and tolerated in our prostate cancer cell lines, we were able to demonstrate that increased NUSAP1 expression increases invasion and migration in vitro, and metastasis in vivo. These modest increases in NUSAP1 levels had no effect on proliferation in vitro and equivocal results on tumor growth in mice. Only one 
A

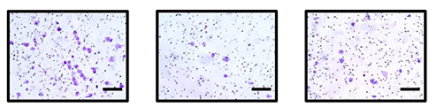

$P<0.0001$

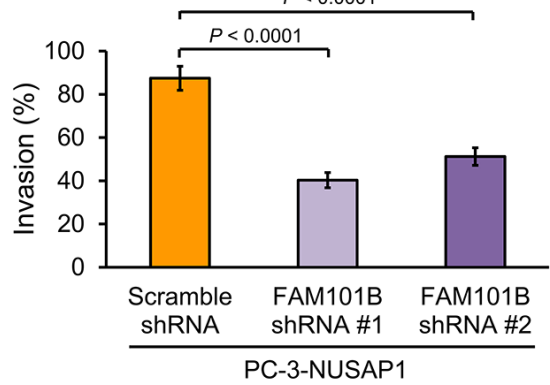

B
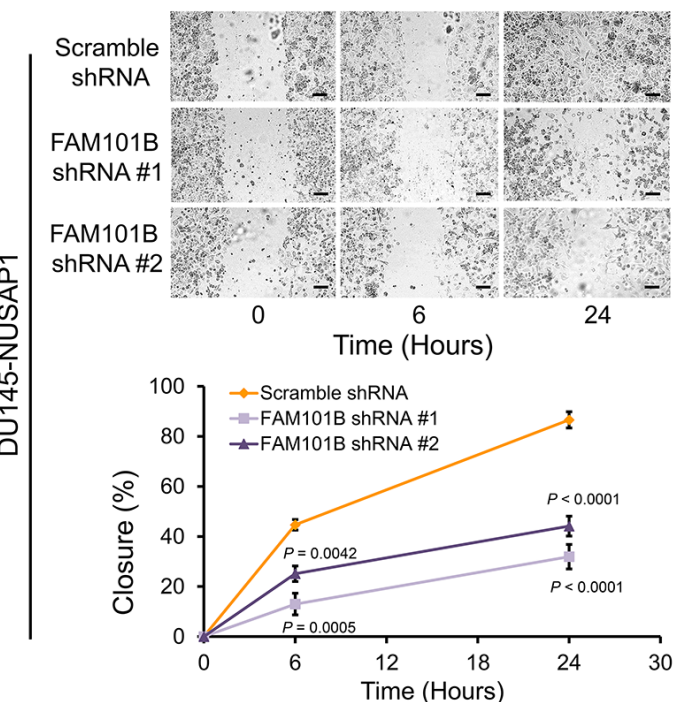

C

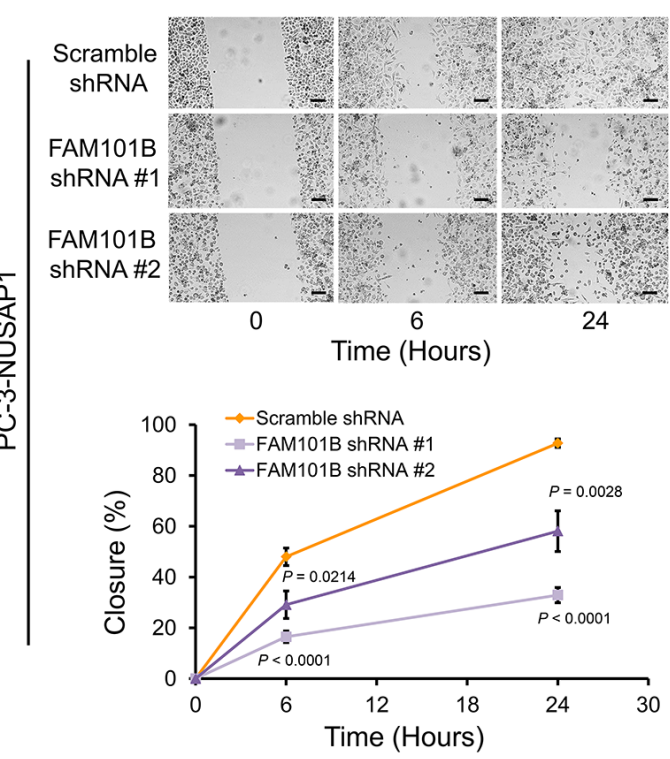

Figure 7: Knockdown of $F A M 101 B$ decreases invasion and migration of prostate cancer cells. A. Invasion assays using Matrigel invasion chambers after lentiviral shRNA knockdown of FAM101B in PC-3-NUSAP1 cells. Representative images show invasion of Matrigel membranes stained with $0.5 \%$ crystal violet. Bars: mean \pm SEM. B and C. Wound healing assays in (B) DU145-NUSAP1 and (C) PC-3-NUSAP1 cells after knockdown of FAM101B versus control. Representative images show wound channel closure over time. The migratory rate was determined by measuring wound channel area as a function of time using NIH Image $\mathrm{J}$ software. Points: mean $\pm \mathrm{SEM}$. All scale bars: $100 \mu \mathrm{m}$. All $P$-values were calculated using the two-tailed Student's t-test. 
previous study in zebrafish has linked nusapl expression to cell migration and is consistent with our findings. When expression of nusapl was depleted in zebrafish embryos by antisense oligonucleotide morpholino microinjection, extensions of the trunk and yolk were impaired, and this impairment was caused by significantly decreased neural crest cell migration [58]. While our effects on metastases are modest, they are consistent with the natural history of prostate cancer, which is slowly progressive and with low proliferative index. The finding of increased NUSAP1 expression levels in metastatic prostate cancer argues strongly for its role in progression.

Modulation of NUSAP1 expression produced changes in gene expression that correlate with the observed changes in invasion, migration, metastases, and clinical outcome. The gene expression patterns elicited by NUSAP1 overexpression or knockdown fall into a remarkably consistent set of pathways related to tumor progression. Interestingly, we identified FAM101B, a TGF $\beta 1$ signaling effector [33], as a potential downstream effector of NUSAP1 in tumor progression. TGF $\beta 1$ is a master regulator of the epithelial to mesenchymal transition, a process that enables tumor invasion and cancer metastasis [59]. Depletion of FAM101B expression in NUSAP1 overexpressing cell lines abolished the effect of increased invasion and migration that results when NUSAP1 is overexpressed. Like NUSAP1, we found that $F A M 101 B$ expression is significantly increased in metastatic patient samples compared to non-cancerous and localized cancer patient samples and correlates with NUSAP1 expression in localized prostate cancer. FAM101B transcripts are also found at medium to high levels in several different cancer cell lines, including neuroblastoma, melanoma, cervical squamous carcinoma, endometrial adenocarcinoma, choriocarcinoma, epidermoid carcinoma, and lymphoma and leukemia cell lines (www.proteinatlas. org/) [60]. Furthermore, FAM101B protein levels are found at medium to high levels in human breast, renal, testis, and prostate cancers [60]. In general, FAM101B and NUSAP1 expression correlate in the cell lines and cancers tested; however, it should be noted that medium to high levels of NUSAP1 expression are found in additional and most cell lines and cancers tested [60]. Our analyses suggest NUSAP1 overexpression may lead to tumor progression in patients, at least in part, via FAM101B. Additional work will be necessary to understand the mechanisms underlying NUSAP1's effects on gene expression and tumor progression. NUSAP1 contains a DNA binding domain $[27,61]$, so it is possible that NUSAP1 directly acts as a transcriptional regulator.

NUSAP1 is a highly validated biomarker of prostate cancer progression [11, 13-16] and overexpressed in multiple cancer types [55]. Our analyses of prostate cancer cell lines and prostate cancer patient samples suggest that NUSAP1 is more than just a prognostic biomarker in prostate cancer, but actually plays a role in driving prostate cancer progression. NUSAP1 appears to drive prostate cancer progression by promoting invasion, migration, and metastasis of prostate cancer by modulating gene expression changes, including modulation of FAM101B. Taken together, our work provides a better understanding of the function of NUSAP1 in aggressive prostate cancers, provides rationale for using NUSAP1 as a prognostic biomarker, and sets the stage for developing improved therapeutic strategies for prostate and other cancers.

\section{MATERIALS AND METHODS}

\section{Cell culture}

Cell lines were grown under standard conditions, used by passage 15, and were originally purchased from ATCC (Manassas, VA, USA) with the exception of the PC-3-luc2 cell line, which was purchased from PerkinElmer (Waltham, MA, USA). DU145, DU145NUSAP1, and HEK 293T cells were grown in DMEM (Life Technologies, Carlsbad, CA, USA). LNCaP cells were grown in T-Medium (Invitrogen, Carlsbad, CA, USA). PC-3 (ATCC), PC-3-luc2 (PerkinElmer), and PC3-NUSAP1 cells were grown in F-12K Nutrient Mixture (Life Technologies). The 22Rv1 cell line was grown in RPMI-1640 Medium (Life Technologies).

\section{Lentiviral production}

Lentiviral particles were produced as described previously [31].

\section{Lentiviral infections}

Lentiviral infections were performed as described previously [31] to overexpress NUSAP1 versus EGFP control, knockdown NUSAP1 versus scramble control, or knockdown $F A M 101 B$ versus scramble control when cells were 10 to $50 \%$ confluent. Antibiotics used for stable selection include puromycin $(1-10 \mu \mathrm{g} / \mathrm{ml})$ or hygromycin B $(100-500 \mu \mathrm{g} / \mathrm{ml})$.

\section{Plasmids}

The pMDL, pRSV, and pMD2.G-VSVG plasmids were gifts from Dr. Julien Sage. The pLKO.1 puro vector with scramble shRNA sequence (Plasmid \#1864) was purchased from Addgene (Cambridge, MA, USA) and deposited by Dr. David Sabatini [62]. Three pLKO.1 puro vectors with NUSAP1 shRNA sequences (clone ID: TRCN0000135909 [NUSAP1 shRNA \#1], clone ID: TRCN0000136422 [NUSAP1 shRNA \#2], and clone ID: TRCN0000137707 [NUSAP1 shRNA \#3]) were purchased from Thermo Fisher Scientific (Waltham, MA, USA). The pReceiver-Lv105 vector with NUSAP1 cDNA (EX-Z29392-Lv105), pReceiver-Lv105 vector with EGFP cDNA (EX-EGFP-Lv105), and three psi-LVRU6MH 
vectors with FAM101B shRNA sequences (HSH00970131-LVRU6MH [FAM101B shRNA \#1] and HSH00970132-LVRU6MH [FAM101B shRNA \#2]) and scramble shRNA sequence (CSHCTR001-LVRU6MH) were purchased from GeneCopoeia (Rockville, MD, USA).

\section{RNA extraction and purification}

Total RNA from cell lines, mouse tissues, and tumors was purified using TRIzol Reagent (Life Technologies) or RNeasy Microarray Tissue Mini Kit (Qiagen) as directed by the manufacturer's protocol. The RNeasy MinElute Cleanup Kit (Qiagen, Valencia, CA, USA) was used to cleanup RNA as directed by the manufacturer's protocol. RNA was subject to DNase treatment using the RNase-Free DNase Set (Qiagen) or TURBO DNA-free Kit (Life Technologies).

\section{RT-qPCR}

RT-qPCR was performed as previously described [31]. Relative gene expression was determined with the $\Delta \mathrm{C}_{\mathrm{T}}$ method using HPRT1 or universal GAPDH reference genes. Primer sequences are listed in Supplementary Table 4.

\section{RNA-Seq and expression analysis}

Lentiviral infections were used to stably overexpress or knockdown NUSAP1 or controls in triplicate in DU145 or PC-3 cell lines. After 72 or 96 hours, total RNA was extracted and purified. Sequencing libraries were prepared with the TruSeq RNA Sample Preparation Kit v2 (Illumina, San Diego, CA, USA) or TruSeq Stranded mRNA Sample Preparation Kit (Illumina) as directed by the manufacturer's protocol. Pooled libraries were run on a HiSeq 2000 Sequencing System (Illumina) with 101 base pair single-end reads. TopHat [63] and Cufflinks [64] software were used to align sequences to the human male (hg19) genome and determine expression levels, respectively. Differentially expressed genes had fold-change $\geq 1.5$ and adjusted $P<0.05$. Ingenuity Pathways Analysis (Qiagen) was used to identify biological functions associated with genes differentially expressed. Gene expression data have been deposited in Gene Expression Omnibus (GEO Accession: GSE80963).

\section{Measurements of cell cycle and apoptosis}

Cells were harvested, fixed in $70 \%$ ethanol, stained with propidium iodide, and run on a BD Accuri C6 Flow Cytometer (BD Biosciences). DNA content from individual cells was analyzed using CFlow Sampler software (BD Biosciences), whereby the percentage of cells in $\mathrm{G} 0 / \mathrm{G} 1$, $\mathrm{G} 2 / \mathrm{M}$, and apoptotic peaks was determined.

\section{Mouse xenograft assay and monitoring}

Procedures with live animals were conducted in accordance with ethical standards and approved by
Stanford University's Institutional Animal Care and Use Committee. Lentiviral infections were used to stably overexpress or knockdown NUSAP1 or controls in PC3-luc2 cells. Cells were harvested, counted using a hemocytometer, and resuspended in equal volumes of PBS and Matrigel (Corning Life Sciences, Corning, NY, USA). One million cells were subcutaneously injected into the left flank of isoflurane anesthetized 4 to 6 week old SCIDbeige male mice (Charles River, Wilmington, MA, USA). Tumor volume was monitored weekly by bioluminescence imaging and caliper measurements. For bioluminescence imaging, luciferase expression was monitored with the IVIS 100 imaging system and Living Image software (PerkinElmer) by imaging mice 10 minutes post intraperitoneal injection of $150 \mathrm{mg} / \mathrm{kg}$ luciferin. Total flux was used to calculate tumor volume over time. For caliper measurements, the length $(l)$, width $(w)$, and height $(h)$ of tumors were measured weekly with a caliper beginning 3 weeks after subcutaneous injection and tumor volume was calculated using the formula: $l \times w \times h \pi \div 6$.

After tumor volume monitoring $(50,59$, or 62 days post injection of cells), mice were euthanized, and tissues and tumor biopsies were extracted and either immediately ex vivo imaged via bioluminescence imaging or saved for later RT-qPCR analysis. To save samples, tissues were stored in RNAlater RNA Stabilization Reagent (Qiagen), Allprotect Tissue Reagent (Qiagen), or a $-80^{\circ} \mathrm{C}$ freezer.

\section{Protein extraction and western blots}

Protein extractions were performed and protein concentrations were determined as described previously [31]. Forty $\mu \mathrm{g}$ of total protein was loaded per lane on $4-20 \% \mathrm{Mini}$ PROTEAN TGX Gels (Bio-Rad Laboratories, Hercules, CA, USA). Western blots were performed using anti-NUSAP1 (1:2,500; 12024-1-AP; Proteintech Group, Rosemont, IL, USA), anti-FAM101B (1:500; ab150350; Abcam, Cambridge, UK), or anti-GAPDH (1:4,000; 10R-G109A; Fitzgerald Industries International, Acton, MA, USA) primary antibodies; and Peroxidase AffiniPure Goat AntiMouse IgG, Light Chain Specific (1:10,000; 115-035-174 Jackson ImmunoResearch Laboratories, Inc., West Grove, PA, USA) or Peroxidase IgG Fraction Monoclonal Mouse Anti-Rabbit IgG, Light Chain Specific (1:5,000 or 1:10,000; 211-032-171; Jackson ImmunoResearch Laboratories, Inc.) secondary antibodies. Western blots were developed and stripped as described previously [31], and visualized using the Mini-Medical/90 film processor (AFP ImageWorks, Elmsford, NY, USA).

\section{Cell proliferation assays}

Cell proliferation was quantified over 5 days using the CellTiter 96 Aqueous One Solution Cell Proliferation Assay (Promega, Madison, WI, USA) as directed by the manufacturer's protocol. 


\section{Cell invasion assays}

Invasion assays were performed with 100,000 DU145 cells overexpressing NUSAP1 or control, 25,000 or 50,000 PC-3 cells overexpressing NUSAP1 or control, or 50,000 or 125,000 PC-3-NUSAP1 cells underexpressing $F A M 101 B$ or control using BD BioCoat Matrigel Invasion Chambers (BD Biosciences) as directed by the manufacturer's protocol with slight modifications as described previously [31]. Images were acquired using a QImaging QICAM digital camera (QImaging, Surrey, BC, Canada) using either a $4 x$ or $10 x$ objective on an Olympus IX51 inverted microscope (Olympus Corporation, Center Valley, PA, USA).

\section{Wound healing assays}

Confluent monolayers of cells were abraded with a pipette tip and monitored for wound channel closure over time. Images were acquired using a QImaging QICAM digital camera (QImaging) using either a 4x or 10x objective on an Olympus IX51 inverted microscope (Olympus Corporation). NIH Image J software was used to measure wound channel area as a function of time.

\section{Data analysis}

Microsoft Excel (Microsoft, Redmond, WA, USA), GraphPad Prism 6 (GraphPad Software, La Jolla, CA, USA), Java TreeView (version 1.1.6rv), SAM [40], and $\mathrm{R}$ (programming language) were used for analysis, to create graphs, or determine means, standard deviations, standard errors, and $P$-values (two-tailed Student's t-test, Mann-Whitney U test, Hypergeometric test, Log-rank test, Fisher's exact test).

\section{ACKNOWLEDGMENTS}

We thank Dr. Donna Peehl for supplying LNCaP cells, Dr. Jonathan Pollack for supplying DU145 cells, and Dr. Julien Sage for supplying HEK 293T cells and vectors to produce lentiviruses. We thank members of the Brooks and Peehl laboratories for advice.

\section{CONFLICTS OF INTEREST}

The authors declare no conflicts of interest.

\section{GRANT SUPPORT}

This project was funded by the USA Department of Defense (W81XWH-10-PCRP-IDA to JDB) and the American Urological Association Urology Care Foundation (Research Scholar Award to CAG).

\section{REFERENCES}

1. Siegel RL, Miller KD, Jemal A. Cancer statistics, 2016. CA Cancer J Clin. 2016; 66:7-30.

2. Welch HG, Gorski DH, Albertsen PC. Trends in Metastatic Breast and Prostate Cancer--Lessons in Cancer Dynamics. N Engl J Med. 2015; 373:1685-1687.

3. Schroder FH, Hugosson J, Roobol MJ, Tammela TL, Ciatto S, Nelen V, Kwiatkowski M, Lujan M, Lilja H, Zappa M, Denis LJ, Recker F, Berenguer A, et al. Screening and prostate-cancer mortality in a randomized European study. N Engl J Med. 2009; 360:1320-1328.

4. Bill-Axelson A, Holmberg L, Filen F, Ruutu M, Garmo $\mathrm{H}$, Busch C, Nordling S, Haggman M, Andersson SO, Bratell S, Spangberg A, Palmgren J, Adami HO, et al. Radical prostatectomy versus watchful waiting in localized prostate cancer: the Scandinavian prostate cancer group-4 randomized trial. J Natl Cancer Inst. 2008; 100:1144-1154.

5. Andriole GL, Crawford ED, Grubb RL 3rd, Buys SS, Chia D, Church TR, Fouad MN, Gelmann EP, Kvale PA, Reding DJ, Weissfeld JL, Yokochi LA, O'Brien B, et al. Mortality results from a randomized prostate-cancer screening trial. N Engl J Med. 2009; 360:1310-1319.

6. Wilt TJ, Brawer MK, Barry MJ, Jones KM, Kwon Y, Gingrich JR, Aronson WJ, Nsouli I, Iyer P, Cartagena R, Snider G, Roehrborn C, Fox S. The Prostate cancer Intervention Versus Observation Trial:VA/NCI/AHRQ Cooperative Studies Program \#407 (PIVOT): design and baseline results of a randomized controlled trial comparing radical prostatectomy to watchful waiting for men with clinically localized prostate cancer. Contemp Clin Trials. 2009; 30:81-87.

7. Moyer VA. Screening for prostate cancer: U.S. Preventive Services Task Force recommendation statement. Ann Intern Med. 2012; 157:120-134.

8. Klotz L, Vesprini D, Sethukavalan P, Jethava V, Zhang L, Jain S, Yamamoto T, Mamedov A, Loblaw A. Long-term follow-up of a large active surveillance cohort of patients with prostate cancer. J Clin Oncol. 2015; 33:272-277.

9. Newcomb LF, Thompson IM Jr., Boyer HD, Brooks JD, Carroll PR, Cooperberg MR, Dash A, Ellis WJ, Fazli L, Feng Z, Gleave ME, Kunju P, Lance RS, et al. Outcomes of Active Surveillance for Clinically Localized Prostate Cancer in the Prospective, Multi-Institutional Canary PASS Cohort. J Urol. 2016; 195:313-320.

10. Tosoian JJ, Mamawala M, Epstein JI, Landis P, Wolf S, Trock BJ, Carter HB. Intermediate and Longer-Term Outcomes From a Prospective Active-Surveillance Program for Favorable-Risk Prostate Cancer. J Clin Oncol. 2015; 33:3379-3385.

11. Gulzar ZG, McKenney JK, Brooks JD. Increased expression of NuSAP in recurrent prostate cancer is mediated by E2F1. Oncogene. 2013; 32:70-77. 
12. Penney KL, Sinnott JA, Fall K, Pawitan Y, Hoshida Y, Kraft P, Stark JR, Fiorentino M, Perner S, Finn S, Calza S, Flavin R, Freedman ML, et al. mRNA expression signature of Gleason grade predicts lethal prostate cancer. J Clin Oncol. 2011; 29:2391-2396.

13. Cooperberg MR, Simko JP, Cowan JE, Reid JE, Djalilvand A, Bhatnagar S, Gutin A, Lanchbury JS, Swanson GP, Stone S, Carroll PR. Validation of a cell-cycle progression gene panel to improve risk stratification in a contemporary prostatectomy cohort. J Clin Oncol. 2013; 31:1428-1434.

14. Cuzick J, Swanson GP, Fisher G, Brothman AR, Berney DM, Reid JE, Mesher D, Speights VO, Stankiewicz E, Foster CS, Moller H, Scardino P, Warren JD, et al. Prognostic value of an RNA expression signature derived from cell cycle proliferation genes in patients with prostate cancer: a retrospective study. Lancet Oncol. 2011; 12:245-255.

15. Erho N, Crisan A, Vergara IA, Mitra AP, Ghadessi M, Buerki C, Bergstralh EJ, Kollmeyer T, Fink S, Haddad Z, Zimmermann B, Sierocinski T, Ballman KV, et al. Discovery and validation of a prostate cancer genomic classifier that predicts early metastasis following radical prostatectomy. PLoS One. 2013; 8:e66855.

16. Ross AE, Feng FY, Ghadessi M, Erho N, Crisan A, Buerki C, Sundi D, Mitra AP, Vergara IA, Thompson DJ, Triche TJ, Davicioni E, Bergstralh EJ, et al. A genomic classifier predicting metastatic disease progression in men with biochemical recurrence after prostatectomy. Prostate Cancer Prostatic Dis. 2014; 17:64-69.

17. Wang Q, Li W, Zhang Y, Yuan X, Xu K, Yu J, Chen Z, Beroukhim R, Wang H, Lupien M, Wu T, Regan MM, Meyer CA, et al. Androgen receptor regulates a distinct transcription program in androgen-independent prostate cancer. Cell. 2009; 138:245-256.

18. Ryu B, Kim DS, Deluca AM, Alani RM. Comprehensive expression profiling of tumor cell lines identifies molecular signatures of melanoma progression. PLoS One. 2007; 2:e594.

19. Bogunovic D, O’Neill DW, Belitskaya-Levy I, Vacic V, Yu YL, Adams S, Darvishian F, Berman R, Shapiro R, Pavlick AC, Lonardi S, Zavadil J, Osman I, et al. Immune profile and mitotic index of metastatic melanoma lesions enhance clinical staging in predicting patient survival. Proc Natl Acad Sci U S A. 2009; 106:20429-20434.

20. Chen DT, Nasir A, Culhane A, Venkataramu C, Fulp W, Rubio R, Wang T, Agrawal D, McCarthy SM, Gruidl M, Bloom $\mathrm{G}$, Anderson T, White J, et al. Proliferative genes dominate malignancy-risk gene signature in histologically-normal breast tissue. Breast Cancer Res Treat. 2010; 119:335-346.

21. Chen L, Yang L, Qiao F, Hu X, Li S, Yao L, Yang XL, Shao ZM. High Levels of Nucleolar Spindle-Associated Protein and Reduced Levels of BRCA1 Expression Predict Poor Prognosis in Triple-Negative Breast Cancer. PLoS One. 2015; 10:e140572.
22. Marie SK, Okamoto OK, Uno M, Hasegawa AP, ObaShinjo SM, Cohen T, Camargo AA, Kosoy A, Carlotti CG Jr., Toledo S, Moreira-Filho CA, Zago MA, Simpson AJ, et al. Maternal embryonic leucine zipper kinase transcript abundance correlates with malignancy grade in human astrocytomas. Int J Cancer. 2008; 122:807-815.

23. Zhang M, Yang D, Liu X, Liu Y, Liang J, He H, Zhong K, Lin L, Tao G, Zhang C, Zhou J. Expression of Nusap1 in the surgical margins of hepatocellular carcinoma and its association with early recurrence. Nan Fang Yi Ke Da Xue Xue Bao. 2013; 33:937-938.

24. Stuart JE, Lusis EA, Scheck AC, Coons SW, Lal A, Perry A, Gutmann DH. Identification of gene markers associated with aggressive meningioma by filtering across multiple sets of gene expression arrays. J Neuropathol Exp Neurol. 2011; 70:1-12.

25. Vanden Bosch A, Raemaekers T, Denayer S, Torrekens S, Smets N, Moermans K, Dewerchin M, Carmeliet P, Carmeliet G. NuSAP is essential for chromatin-induced spindle formation during early embryogenesis. J Cell Sci. 2010; 123:3244-3255.

26. Raemaekers T, Ribbeck K, Beaudouin J, Annaert W, Van Camp M, Stockmans I, Smets N, Bouillon R, Ellenberg J, Carmeliet G. NuSAP, a novel microtubule-associated protein involved in mitotic spindle organization. J Cell Biol. 2003; 162:1017-1029.

27. Verbakel W, Carmeliet G, Engelborghs Y. SAP-like domain in nucleolar spindle associated protein mediates mitotic chromosome loading as well as interphase chromatin interaction. Biochem Biophys Res Commun. 2011; 411:732-737.

28. Ribbeck K, Groen AC, Santarella R, Bohnsack MT, Raemaekers T, Kocher T, Gentzel M, Gorlich D, Wilm M, Carmeliet G, Mitchison TJ, Ellenberg J, Hoenger A, et al. NuSAP, a mitotic RanGTP target that stabilizes and cross-links microtubules. Mol Biol Cell. 2006; 17:2646-2660.

29. Li C, Zhang Y, Yang Q, Ye F, Sun SY, Chen ES, Liou YC. NuSAP modulates the dynamics of kinetochore microtubules by attenuating MCAK depolymerisation activity. Sci Rep. 2016; 6:18773.

30. Li C, Xue C, Yang Q, Low BC, Liou YC. NuSAP governs chromosome oscillation by facilitating the Kid-generated polar ejection force. Nat Commun. 2016; 7:10597.

31. Gordon CA, Gulzar ZG, Brooks JD. NUSAP1 expression is upregulated by loss of RB1 in prostate cancer cells. Prostate. 2015; 75:517-526.

32. Sharma A, Yeow WS, Ertel A, Coleman I, Clegg N, Thangavel C, Morrissey C, Zhang X, Comstock CE, Witkiewicz AK, Gomella L, Knudsen ES, Nelson PS, et al. The retinoblastoma tumor suppressor controls androgen signaling and human prostate cancer progression. J Clin Invest. 2010; 120:4478-4492. 
33. Gay O, Gilquin B, Nakamura F, Jenkins ZA, McCartney R, Krakow D, Deshiere A, Assard N, Hartwig JH, Robertson SP, Baudier J. RefilinB (FAM101B) targets filamin A to organize perinuclear actin networks and regulates nuclear shape. Proc Natl Acad Sci U S A. 2011; 108:11464-11469.

34. Mizuhashi K, Kanamoto T, Moriishi T, Muranishi Y, Miyazaki T, Terada K, Omori Y, Ito M, Komori T, Furukawa T. Filamin-interacting proteins, $\mathrm{Cfm} 1$ and $\mathrm{Cfm} 2$, are essential for the formation of cartilaginous skeletal elements. Hum Mol Genet. 2014; 23:2953-2967.

35. Jones E, Pu H, Kyprianou N. Targeting TGF-beta in prostate cancer: therapeutic possibilities during tumor progression. Expert Opin Ther Targets. 2009; 13:227-234.

36. Yu YP, Landsittel D, Jing L, Nelson J, Ren B, Liu L, McDonald C, Thomas R, Dhir R, Finkelstein S, Michalopoulos G, Becich $\mathrm{M}$, Luo JH. Gene expression alterations in prostate cancer predicting tumor aggression and preceding development of malignancy. J Clin Oncol. 2004; 22:2790-2799.

37. Chandran UR, Ma C, Dhir R, Bisceglia M, Lyons-Weiler M, Liang W, Michalopoulos G, Becich M, Monzon FA. Gene expression profiles of prostate cancer reveal involvement of multiple molecular pathways in the metastatic process. BMC Cancer. 2007; 7:64.

38. Varambally S, Yu J, Laxman B, Rhodes DR, Mehra R, Tomlins SA, Shah RB, Chandran U, Monzon FA, Becich MJ, Wei JT, Pienta KJ, Ghosh D, et al. Integrative genomic and proteomic analysis of prostate cancer reveals signatures of metastatic progression. Cancer Cell. 2005; 8:393-406.

39. Valta MP, Zhao H, Ingels A, Thong AE, Nolley R, Saar $\mathrm{M}$, Peehl DM. Development of a realistic in vivo bone metastasis model of human renal cell carcinoma. Clin Exp Metastasis. 2014; 31:573-584.

40. Tusher VG, Tibshirani R, Chu G. Significance analysis of microarrays applied to the ionizing radiation response. Proc Natl Acad Sci U S A. 2001; 98:5116-5121.

41. Glinsky GV, Glinskii AB, Stephenson AJ, Hoffman RM, Gerald WL. Gene expression profiling predicts clinical outcome of prostate cancer. J Clin Invest. 2004; 113:913-923.

42. Taylor BS, Schultz N, Hieronymus H, Gopalan A, Xiao Y, Carver BS, Arora VK, Kaushik P, Cerami E, Reva B, Antipin Y, Mitsiades N, Landers T, et al. Integrative genomic profiling of human prostate cancer. Cancer Cell. 2010; 18:11-22.

43. Cerami E, Gao J, Dogrusoz U, Gross BE, Sumer SO, Aksoy BA, Jacobsen A, Byrne CJ, Heuer ML, Larsson E, Antipin Y, Reva B, Goldberg AP, et al. The cBio cancer genomics portal: an open platform for exploring multidimensional cancer genomics data. Cancer Discov. 2012; 2:401-404.

44. Gao J, Aksoy BA, Dogrusoz U, Dresdner G, Gross B, Sumer SO, Sun Y, Jacobsen A, Sinha R, Larsson E, Cerami E, Sander C, Schultz N. Integrative analysis of complex cancer genomics and clinical profiles using the cBioPortal. Sci Signal. 2013; 6:pl1.
45. Bookstein R, Rio P, Madreperla SA, Hong F, Allred C, Grizzle WE, Lee WH. Promoter deletion and loss of retinoblastoma gene expression in human prostate carcinoma. Proc Natl Acad Sci U S A. 1990; 87:7762-7766.

46. Brooks JD, Bova GS, Isaacs WB. Allelic loss of the retinoblastoma gene in primary human prostatic adenocarcinomas. Prostate. 1995; 26:35-39.

47. Phillips SM, Barton CM, Lee SJ, Morton DG, Wallace DM, Lemoine NR, Neoptolemos JP. Loss of the retinoblastoma susceptibility gene (RB1) is a frequent and early event in prostatic tumorigenesis. Br J Cancer. 1994; 70:1252-1257.

48. Bubendorf L, Kononen J, Koivisto P, Schraml P, Moch H, Gasser TC, Willi N, Mihatsch MJ, Sauter G, Kallioniemi OP. Survey of gene amplifications during prostate cancer progression by high-throughout fluorescence in situ hybridization on tissue microarrays. Cancer Res. 1999; 59:803-806.

49. Edwards J, Krishna NS, Grigor KM, Bartlett JM. Androgen receptor gene amplification and protein expression in hormone refractory prostate cancer. Br J Cancer. 2003; 89:552-556.

50. Koivisto P, Kononen J, Palmberg C, Tammela T, Hyytinen E, Isola J, Trapman J, Cleutjens K, Noordzij A, Visakorpi T, Kallioniemi OP. Androgen receptor gene amplification: a possible molecular mechanism for androgen deprivation therapy failure in prostate cancer. Cancer Res. 1997; 57:314-319.

51. Linja MJ, Savinainen KJ, Saramaki OR, Tammela TL, Vessella RL, Visakorpi T. Amplification and overexpression of androgen receptor gene in hormone-refractory prostate cancer. Cancer Res. 2001; 61:3550-3555.

52. Visakorpi T, Hyytinen E, Koivisto P, Tanner M, Keinanen R, Palmberg C, Palotie A, Tammela T, Isola J, Kallioniemi OP. In vivo amplification of the androgen receptor gene and progression of human prostate cancer. Nat Genet. 1995; 9:401-406.

53. Waltering KK, Helenius MA, Sahu B, Manni V, Linja MJ, Janne OA, Visakorpi T. Increased expression of androgen receptor sensitizes prostate cancer cells to low levels of androgens. Cancer Res. 2009; 69:8141-8149.

54. Chen CD, Welsbie DS, Tran C, Baek SH, Chen R, Vessella R, Rosenfeld MG, Sawyers CL. Molecular determinants of resistance to antiandrogen therapy. Nat Med. 2004; 10:33-39.

55. Iyer J, Moghe S, Furukawa M, Tsai MY. What's Nu(SAP) in mitosis and cancer? Cell Signal. 2011; 23:991-998.

56. Li L, Zhou Y, Sun L, Xing G, Tian C, Sun J, Zhang L, He F. NuSAP is degraded by APC/C-Cdh1 and its overexpression results in mitotic arrest dependent of its microtubules' affinity. Cell Signal. 2007; 19:2046-2055.

57. Okamoto A, Higo M, Shiiba M, Nakashima D, Koyama T, Miyamoto I, Kasama H, Kasamatsu A, Ogawara K, Yokoe H, Tanzawa H, Uzawa K. Down-Regulation of Nucleolar and Spindle-Associated Protein 1 (NUSAP1) Expression 
Suppresses Tumor and Cell Proliferation and Enhances Anti-Tumor Effect of Paclitaxel in Oral Squamous Cell Carcinoma. PLoS One. 2015; 10:e0142252.

58. Nie J, Wang H, He F, Huang H. Nusap1 is essential for neural crest cell migration in zebrafish. Protein Cell. 2010; 1:259-266.

59. Nakazawa M, Kyprianou N. Epithelial-mesenchymaltransition regulators in prostate cancer: Androgens and beyond. J Steroid Biochem Mol Biol. 2017; 166:84-90.

60. Uhlen M, Fagerberg L, Hallstrom BM, Lindskog C, Oksvold P, Mardinoglu A, Sivertsson A, Kampf C, Sjostedt E, Asplund A, Olsson I, Edlund K, Lundberg E, et al. Proteomics. Tissue-based map of the human proteome. Science. 2015; 347:1260419.
61. Ribbeck K, Raemaekers T, Carmeliet G, Mattaj IW. A role for NuSAP in linking microtubules to mitotic chromosomes. Curr Biol. 2007; 17:230-236.

62. Sarbassov DD, Guertin DA, Ali SM, Sabatini DM. Phosphorylation and regulation of Akt/PKB by the rictormTOR complex. Science. 2005; 307:1098-1101.

63. Trapnell C, Pachter L, Salzberg SL. TopHat: discovering splice junctions with RNA-Seq. Bioinformatics. 2009; 25:1105-1111.

64. Trapnell C, Williams BA, Pertea G, Mortazavi A, Kwan G, van Baren MJ, Salzberg SL, Wold BJ, Pachter L. Transcript assembly and quantification by RNA-Seq reveals unannotated transcripts and isoform switching during cell differentiation. Nat Biotechnol. 2010; 28:511-515. 